\title{
Spectrographic analysis of the effect of vocal warm-up on the voice of choir girls
}

\section{Análise espectrográfica do efeito do aquecimento vocal na voz de meninas de coro}

\author{
Lília Maria Gomes Falcão', Maria Lúcia Vaz Masson², Gisele Oliveira', Mara Behlau
}

\begin{abstract}
Purpose: To analyse the immediate effect of a vocal warm-up program on children that sang in a choir by means of spectrographic analysis. Methods: Experimental study consisting of 14 girls from an amateur children's choir, aged 9 to 12 years. Acoustic spectrographic analyses were performed before and after a specific vocal warm-up program, consisting of a hierarchical sequence of body exercises, respiratory and articulation training, vocal exercises, ascending and descending musical scales and facilitating sounds. The speech material for spectrographic analysis was the sustained $/ \mathcal{E}$ :/ vowel, pre and post warm-up program. The selected acoustic parameters were instability of trace, noise at low and high frequencies, frequency bifurcation, harmonics series, presence of a hard vocal attack, pitch and voice breaks, and mean fundamental frequency. Results: No significant differences were found regarding the effect of the vocal warm-up when pre and post data were compared. However, there was a negative correlation between the level of harmonics and noise in the high frequencies post warm-up. Conclusion: The vocal warm-up program implemented for children that sang in choirs produced a richer acoustic spectrum that may indicate enhanced glottic closure or vocal tract adjustment.
\end{abstract}

Keywords: Voice; Speech acoustics; Voice training; Child; Music

\begin{abstract}
RESUMO
Objetivo: Analisar o efeito imediato do aquecimento vocal em crianças cantoras, por meio de análise acústica espectrográfica. Métodos: Estudo de natureza experimental com 14 meninas de um coro infantil amador, com idades entre 9 e 12 anos. Foi realizada avaliação acústica espectrográfica antes e após a utilização de um programa de aquecimento vocal, em uma sequência hierarquizada de atividades, incluindo exercícios corporais, treino respiratório e articulatório, exercícios de produção vocal com escalas ascendentes e descendentes e sons facilitadores. Foi realizada gravação da vogal sustentada /E:/ nos momentos pré e pós-aquecimento vocal, para análise espectrográfica dos seguintes parâmetros: instabilidade do traçado, ruído nas frequências baixas e altas, bifurcação de frequência, série de harmônicos, presença de ataque vocal brusco, quebras de frequência e de sonoridade. Também foi analisada a média da frequência fundamental. Resultados: Não foram encontradas diferenças em relação ao efeito do aquecimento vocal entre os momentos pré e pós-aquecimento, porém, no momento pós-aquecimento vocal, observou-se correlação negativa de grau bom entre número de harmônicos e ruído nas frequências altas. Conclusão: $\mathrm{O}$ aquecimento vocal em meninas coristas produziu maior riqueza no espectro acústico, indicando provável melhora na coaptação glótica, ou em ajuste do trato vocal.
\end{abstract}

Descritores: Voz; Acústica da fala; Treinamento da voz; Criança; Música

Study conducted at the Instituto de Educação Musical - IEM - Salvador (BA), Brazil and at the Centro de Estudos da Voz - CEV - São Paulo (SP), Brazil.

(1) Centro de Estudos da Voz - CEV - São Paulo (SP), Brazil.

(2) Universidade Federal da Bahia - UFBA - Salvador (BA), Brazil.

Conflict of interests: No

Authors' contribution: $L M G F$ study design, collection, analysis and interpretation of data, article wording; $M L V M$ study design, writing and revision of the article, analysis and interpretation of data; $G O$ conception and design of the study, writing and revision of the article, final approval of the version to be published; $M B$ conception and design of the study, correction of the manuscript and final approval of the version to be published.

Correspondence address: Lília Maria Gomes Falcão. R. Oito de Dezembro, 720/502, Edifício Senhor Timóteo, Graça, Salvador (BA), Brazil, CEP: 40150-000. E-mail:lfalcaofono@yahoo.com.br

Received on: 2/3/2014; Accepted on: 9/3/2014 


\section{INTRODUCTION}

The practice of singing during childhood, specifically participation in choirs, enriches the education of the child ${ }^{(1)}$. This activity promotes the development of musicality, auditory perception and musical sensitivity. When children perform musical activities together, the sense of participation and cooperation is stimulated ${ }^{(2,3)}$. Choral singing for children has the ability to produce positive effects in relation to physiological, psychological, social, and cultural aspects, as long as it is performed in an appropriate and pleasant manner, and without straining the children's vocal tract ${ }^{(1,3-5)}$.

When a child is appropriately instructed to avoid vocal effort in choir, the consequences are positive and rewarding. Some authors state that the practice of vocal warm-up provides significant improvement to vocal parameters, both in the prevention and treatment of patients with dysphonia ${ }^{(1,6)}$.

The professional literature considers vocal warm-up to be essential in preparing the vocal tract and its components prior to the singing activity, when more resistance and vocal power are required. The gradual increase of muscle activation, promoted by warm-up exercises of the vocal folds, results in a greater blood supply to the region, which prepares the system for more intense vocal use ${ }^{(7)}$. Vocal warm-up programs result in an observable increase in mobilisation of the mucosa, production of high-pitched and stronger sounds, better vocal quality, as well as better intonation, greater respiratory support and reduction of vocal fatigue ${ }^{(1,4-7)}$. Some authors consider vocal warm-up essential for maintaining vocal stability, providing a better singing performance, greater sound homogeneity, and increasing vocal intensity and projection with a greater number of harmonics ${ }^{(1,6,7)}$. A number of studies have reported improvements in several vocal aspects, such as vocal quality and projection ${ }^{(1,7)}$; they demonstrate positive results in the balance of resonance, articulation, clarity of emission and projection improvement ${ }^{(7)}$. However, there is a lack of scientific literature regarding the analysis of vocal warm-up as pertaining to the voice of singing children.

The aim of this study was to analyse the immediate effect of a vocal warm-up program on the voices of girls from an amateur choir, by means of acoustic spectrographic analysis of selected parameters, in addition to the analysis of the fundamental frequency.

\section{METHODS}

This is an exploratory study of an experimental nature, conducted pre- and post-rehearsal, with a single group. Based on convenience, 14 girls with a mean age of 10.5 years (range 9 to 12 years 11 months) were selected. The girls were volunteers from a children's choir in a private musical school in the city of Salvador (BA). The choir members were invited to participate in the study through their legal representatives, who signed an Informed Consent Form. This study was approved by the Research Ethics Committee of the Centro de Estudos da Voz (CEV), under statute 1317/09.

The inclusion criterion was girls that had not begun menstruating; this was to prevent the interference of hormonal factors on vocal production. Girls with flu or cold symptoms or allergic reactions were temporarily excluded at the time of data collection to avoid any confounding variables in the vocal analysis. Once recovered, they resumed they participation in the recording.

The participants had no complaints regarding vocal alteration prior to completion of the procedure. They had an average of 36 (12-48) months of choir activity, whether continuous or not, with a one-hour weekly rehearsal with the same conductor, divided as follows: ten minutes of vocalise, consisting of ascending and descending scales; arpeggios with vowels and solfège with songs from the choir's repertoire; 40 minutes of repertoire rehearsing; ten final minutes of physical activities, involving movement with songs, playback and creating rhythmic flows, and other musical experiences.

The participants used a pre-established vocal warm-up program, based on activities established by several sources: Vocal Warm-up and Cool-down Program (PAD) ${ }^{(6)}$, procedures for vocal preparation of choir members ${ }^{(8)}$ and Minimum Physiological Vocal Warm-up and Cool-down Program ${ }^{(9)}$. The programs followed a hierarchical and sequential order of implementation, ranging from activities aimed at greater body awareness (breathing and posture), to more specific exercises for vocal production and emission ${ }^{(5,10)}$ (Appendix 1).

In order to implement the vocal warm-up program, the exercises were divided into general and specific, and arranged in a series with a specified number of repetitions, as detailed in Appendix 1. The program began with general exercises, which consisted of body and cervical elongation and breathing exercises, to provide better body posture and prepare and involve the participant in the rehearsal atmosphere. The aim of these exercises was to increase readiness and mental focus on the musical activity and provide better direction of air flow and air output control; essential conditions for singing and richer sound production. Together with general breathing, body and cervical stretching exercises, articulation exercises were also performed to provide greater accuracy and clarity in the emission of sounds ${ }^{(5,8,9)}$ (Appendix 1).

Then specific exercises, aimed at mobilising and relaxing the mucosa, were performed additionally for better glottic closure $^{(6)}$. Such exercises included tongue or lip vibration at an average frequency, as suggested by the researcher. For vocal projection, exercises of bilabial nasal sound emission $/ \mathrm{m} /$ were performed. In order to enhance sound modulation and provide greater vocal extension, glissando exercises (ascending and descending) were performed, as well as hyperacute sounds (fine blowing-sound) and vocalise with facilitating sounds, transposed from semitone to semitone, in the form of an 
arpeggio, starting from $\mathrm{do}_{3}(\mathrm{fO}=261.63 \mathrm{~Hz})$ to $\mathrm{la}_{3}(\mathrm{f} 0=440 \mathrm{~Hz})$, and $\mathrm{mi}_{4}(\mathrm{f} 0=659.26 \mathrm{~Hz})$ as the last note ${ }^{(11)}$. A Casio ${ }^{\circledR} \mathrm{CA}-110$ keyboard was used to monitor the vocalisations. The average duration of the vocal warm-up program was 13 min (ranging from 11 to $15 \mathrm{~min}$ ).

Vocal evaluation was performed by recording, a sustained vowel /E:/, performed comfortably pre-and post-warm-up, prior to any rehearsal activity. The recording of vocal samples was conducted with a Compaq Presario C730BR Intel Pentium Dual Core laptop computer, with a Multilaser microphone installed on a stand, using the Sound Forge 9.0 program, in a semi-acoustically isolated environment with noise levels less than $53 \mathrm{~dB}$ (systematically measured with a digital decibel meter, Radio Shack ${ }^{\circledR}$ Digital Sound Level Meter model). The distance between the microphone and the participant during the recording of the sustained vowel was $5 \mathrm{~cm}$. The samples were recorded with a frequency range of $44.100 \mathrm{~Hz}$ and analysed by means of the VoxMetria 3.3h program, set in vocal quality mode.

To calculate the fundamental frequency, the vocal analysis in the "statistics" tab of the VoxMetria program (version 3.3) was used. Acoustic parameters based on Leão's study ${ }^{(12)}$ were selected for spectrographic analysis. These are detailed below, together with their operational definition in brackets: trace instability (fluctuation in fundamental frequency and/or in spectral trace irregularity); bifurcation of fundamental frequency (presence of sub-harmonics, such as one or more lines between harmonics); noise at both low and high frequencies (presence of noise at frequencies below $2 \mathrm{kHz}$ and above $4 \mathrm{kHz}$, respectively); harmonics series (number of harmonics from the fundamental frequency); frequency break (ascending or descending changes to the fundamental frequency and/or trace); phonatory breaks (interruption and/or absence in fundamental frequency and/or trace) and hard vocal attack (more intense and higher signal, clearly identified spectrographically, at the start of the emission) $)^{(12)}$.

The spectrographic analysis was carried out by the main researcher. The spectrographic boards were presented in random order, paired by participant, without access to the corresponding voice and without an indication of the time of recording (pre or post-warm-up). The analysis was performed twice, to confirm the responses, and six randomly selected samples (20\%) were repeated to evaluate internal concurrence.

The instability parameters of the trace, frequency bifurcation, noise at both low and high frequencies and number of harmonics were analysed by means of a visual analogue scale of $100 \mathrm{~mm}$, in which " 0 " indicated the absence of the parameter and "100," maximum presence of the parameter. The results were expressed as averages. The presence of frequency or phonatory breaks and hard vocal attack was analysed by means of the dichotomous categorical answers "present" and "absent", revealed by the percentage of occurrence.

Finally, statistical associations between the parameters evaluated in samples pre-and post-vocal warm-up were assessed using the Statistical Package for the Social Sciences (SPSS) program, version 11.0. The analysis of continuous response variables (f0, trace instability, frequency bifurcation, noise at both low and high frequencies and number of harmonics) was performed by means of the Wilcoxon Test. For the dichotomous response variables (frequency break, phonatory break and hard vocal attack) using a "present" or "absent" response, the Pearson's Chi-square test was used. To calculate the association matrix between parameters, Spearman's Rank Correlation (rho) was used, with the following degrees: $\angle 20 \%=$ poor; 21 to $40 \%$ $=$ minimal; 41 to $60 \%=$ fair; 61 to $80 \%=$ good; above $81 \%=$ excellent, ranging from negative (-1) to positive (1). To check for internal consistency, the Cronbach's Alpha test was used. The level of significance was set at $5 \%$.

\section{RESULTS}

Initially, the research included 18 girls aged 9 to 12 years, who belonged to a children's choir in a musical private school in Salvador (BA). All 18 girls agreed to participate in the study, but four were excluded as they did not meet the inclusion criteria established, i.e. they had already begun menstruating, a condition that could affect the results.

At the pre-intervention stage, the girls presented adequate vocal quality, without diagnostic identification of any change (Table 1).

When comparing the pre and post-intervention periods, the results did not show any differences for the following spectrographic acoustic parameters: trace instability, fundamental frequency bifurcation, noise at both low and high frequencies, number of harmonics, frequency and phonatory breaks and the presence or absence of hard vocal attack. In addition, no difference was observed in the average fundamental frequency (Tables 1 and 2).

The statistical analysis showed a negative correlation between the number of harmonics and the presence of noise at high frequencies $\left(\mathrm{r}_{\mathrm{s}}=-0.78\right)$, post vocal-warm up (Table 3).

Analysis of the continuous response variables demonstrated high reliability (Cronbach's Alpha $>0.65$ ) in six of the eight parameters analysed. The inter-rater agreement test (concurrence), for the analysis of dichotomous response variables, presented a significant $\alpha$ (83 to $100 \%)$.

\section{DISCUSSION}

Current studies involving spectrographic analysis of pre-pubescent children's voices are still quite scarce and preliminary in nature, demonstrating the difficulty in establishing parameters for reliable assessment of this age group.

Vocal warm-up was expected to modify acoustic parameters since reports in the professional literature have indicated that vocal warm-up promotes changes in vocal quality by 
Table 1. Objective measurements and spectrographic parameters in pre and post vocal-warm-up samples

\begin{tabular}{lccc}
\hline Parameters & Pre-warming up & Post-warming up & p-value \\
\hline F0(Hz) & 234.05 & 246.36 & 0.510 \\
Trace instability & 50.36 & 46.14 & 0.490 \\
Frequency bifurcation & 14.86 & 12.14 & 0.330 \\
Noise at low frequencies & 57.50 & 43.29 & 0.087 \\
Noise at high frequencies & 53.57 & 56.43 & 0.866 \\
Harmonics series & 42.50 & 46.14 & 0.778 \\
\hline
\end{tabular}

Wilcoxon test $(p<0.05)$

Note: $f 0$ = fundamental frequency

Table 2. Percentage of dichotomous response parameters in the samples of the girls' choir group pre- and post vocal-warm-up

\begin{tabular}{lcccc}
\hline \multirow{2}{*}{ Parameters } & & Pre-warming up & Post-warming up & p-value \\
\cline { 3 - 5 } & & $\%$ & $\%$ & 71.4 \\
Quebra de frequência & Present & 64.3 & 28.6 & 0.455 \\
& Absent & 35.7 & 78.6 & 21.4 \\
Quebra de sonoridade & Present & 92.9 & 57.1 & 0.786 \\
& Absent & 7.1 & 71.4 & 0.406 \\
\hline \multirow{2}{*}{ Ataque vocal brusco } & Present & 28.6 & 42.9 & \\
\hline
\end{tabular}

Pearson's Chi-square test $(p<0.05)$

Table 3. Association matrix between spectrographic parameters in pre- and post-warm-up samples

\begin{tabular}{|c|c|c|c|c|}
\hline Parameters & Instability & $\begin{array}{l}\text { Frequency } \\
\text { bifurcation }\end{array}$ & $\begin{array}{l}\text { Noise at low } \\
\text { frequencies }\end{array}$ & $\begin{array}{l}\text { Noise at high } \\
\text { frequencies }\end{array}$ \\
\hline \multicolumn{5}{|l|}{ Pre-warm up } \\
\hline Noise at low frequencies & 0.41 & - & - & - \\
\hline Noise at high frequencies & 0.47 & - & - & - \\
\hline Harmonics series & 0.34 & 0.38 & 0.45 & -0.23 \\
\hline \multicolumn{5}{|l|}{ Post-warm up } \\
\hline Noise at low frequencies & 0.19 & - & - & - \\
\hline Noise at high frequencies & -0.67 & - & - & - \\
\hline Harmonics series & -0.12 & -0.13 & -0.38 & $-0.78^{*}$ \\
\hline
\end{tabular}

*Significant values $(p=0.02)$ - Spearman Rank Correlation

increasing the fundamental frequency and preparing the voice for more intense use in a more acute pitch, providing greater projection, stability and performance ${ }^{(1,4-7)}$. However, the results of the acoustic spectrographic analysis showed no difference in spectrographic parameters, in a comparison of pre-and post-vocal warm-up samples. It is possible that a greater number of test subjects, or the analysis of additional parameters would provide different data.

The importance of vocal warm-up for improving the vocal quality of voice professionals has been established in the literature. This is done by modifying parameters required for better performance; these changes relate to vocal aspects, such as stability, better performance, singing uniformity, more vocal projection and better articulation ${ }^{(1,4-7)}$. However, in regards to children's voices, there is no consensus in the research data, or any evidence based on acoustic assessment. Vocal warmup, based on a hierarchical sequence of procedures, provides greater flexibility of the mucosa, with production of more acute and intense sounds of better quality, as well as the reduction of vocal fatigue, aspects that are essential to singing ${ }^{(5,7)}$. The girls' voices did not demonstrate a significant change between pre and post vocal warm-up in regards to the spectrographic parameters studied; perceptual auditory analysis of the voices, visual observation and identification of possible changes in parameters, was not conducted. It must also be remembered that, in addition to possible physiological impacts, warm-up offers a mental function, providing focus and concentration for the activity to follow. 
Studies conducted with children observed that the average Brazilian fundamental frequency (f0) of children's voices, in the 8 to 12 years age group, ranges from 230 to $236 \mathrm{~Hz}^{(9,13)}$. In this study, the fundamental frequency prior to vocal warm-up was close to this average. Comparing the pre and post-warm-up samples, no difference was observed in fundamental frequency (Table 1). In a previous study conducted with 18 children participating in choral activities, on vocal pre-change, there were no significant differences in the fundamental frequency average between pre-and post-procedures of the Warm-up and Cool-down Program (DBP) ${ }^{(1)}$ either.

In another study conducted with children, more than half (53.4\%) presented hard vocal attack, a common characteristic in populations of similar age ${ }^{(14)}$. In this study, the majority of children showed hard vocal attack prior to vocal warm-up; post warm-up this manifestation tended to be softened (Table 2). This was probably due to the exercises promoting greater vocal stability, especially at the beginning of the emission. However, the occurrence of hard attacks is still high and should probably be considered a typical characteristic of childhood.

No differences were found in the comparison between the pre and post-warm-up periods in the following spectrographic parameters: trace instability, fundamental frequency bifurcation, noise at both low and high frequencies, harmonics series, frequency break, phonatory break, hard vocal attack and fundamental frequency. This indicates that the proposed exercises had no impact, at least in terms of the parameters related to this analysis.

Vocal warm-up was expected to make children's voices exhibit a more stable and organised trace in the spectrographic record. However, the data obtained indicate that two options are required in order to provide an acoustically identifiable voice tag: the need to develop a longer warm-up program, or the use of different exercises from those proposed.

When the relation between the variables in this study was assessed, a good degree of negative correlation between the number of harmonics and the amount of noise at high frequencies was observed in the post-warm-up samples, similar to results observed in another study ${ }^{(12)}$. The presence of a series rich in harmonics indicates better glottic closure ${ }^{(12)}$, inversely proportional to the presence of noise caused by the exhaust of transglottal air, decreasing the frequency of vocal buzzing sounds with greater definition of the harmonics ${ }^{(15,16)}$. The inverse relationship found between the amount of noise at high frequencies and the number of harmonics in the post warm-up samples, suggests that there was a more complete glottic closure, or even a better adjustment of the vocal tract. In addition, the tendency towards a reduction of hard vocal attacks is also a direct indicator of better balance of the glottal source $^{(14)}$. Pre-pubescent boys and girls, despite having similar voices, share some distinct characteristics of vocal behaviour. For example, boys tend to present vocal hyperfunctionality with greater respiratory intake for more intense voice production, while girls show more breathiness ${ }^{(17-19)}$. Although these data are observed in the clinical setting as well as the studies cited, there is no consensus regarding children's voices; some authors do not confirm a higher occurrence of breathiness in girls' voices when compared to boys' voices in the same choir ${ }^{(20)}$.

The warm-up procedure seems to have reduced the breathiness inherent to girls' voices, enabling greater glottic closure. Baken and Orlikoff (2000) reported that breathy voices feature noise more often in the higher ranges of the spectrogram ${ }^{(12)}$. The results obtained in our study suggest that the girls in the group analysed demonstrated lower occurrence of breathy voice in the emission of high-pitched sounds, post the vocal warm-up procedure, indicative of a better glottic closure.

Tension in voice use produces more efficient glottic closure, generating a richer harmonic series, despite the regular presence of instability in the spectral trace ${ }^{(12,15)}$. Tense voices may at times be confused with normal voices in the spectrographic trace, since the presence of harmonics in the upper range of the spectrum is associated both with good vocal quality by the frequency of the vocal folds and appropriate mobilisation of the mucosa, and with the presence of a certain vocal tension ${ }^{(12,21)}$.

It is possible that extending the warm-up exercises for a longer time, could have resulted in a positive impact on the trace stability. According to the literature, warm-up promotes the production of more intense sounds ${ }^{(7)}$, which means more tension from the mechanism and greater number of harmonics ${ }^{(12)}$.

The professional literature shows that the effects of vocal warm-up on singing children are not consistent or similar and are not easily identified ${ }^{(22)}$. Data on children's voices are still scarce; although evaluation in children is important and contributes to the detection of possible vocal alterations, there are recognised possibilities and limitations. The evaluation process is difficult because of the lack of specific proposals and normative data - even more so when considering singing children between 6 and 14 years of age ${ }^{(22,23)}$, as well as the lack of systematisation in the procedures used to obtain normative values for assessment, considering age and voice use. The difficulty in reaching a consensus among acoustics researchers demonstrates the need to use systematic procedures and to associate them with other types of assessment, such as perceptual auditory and physiological ${ }^{(23)}$.

This study demonstrates the limitation of a small number of participants without using data from a control group, in addition to not having considered other types of assessment, such as the perceptual auditory or even the larynx examination. These factors may have hindered the observation of more significant differences and do not allow for a generalisation of the results.

\section{CONCLUSION}

This study identified small immediate changes in the voice of singing girls submitted to a specific vocal warm-up program. This warm-up produced a greater richness in the sound 
spectrum, indicating a likely improvement in glottic closure or adjustment of the vocal tract.

\section{ACKNOWLEDGEMENTS}

The authors wish to acknowledge the Director of the Instituto de Educação Musical (IEM), Prof. Carmen Maria Mettig Rocha, for collaborating in the research and allowing her choir students to participate.

The parents and/or guardians of the students for their trust.

Prof. Dr. Carlos Alberto Lima da Silva, for his valuable contribution to the statistical analyses.

\section{REFERENCES}

1. Pela SM, Ávila CRB, Behlau M. Análises de parâmetros vocais pré e pós-aquecimento vocal em coralistas. Fono Atual. 2000;13(3):26-32.

2. Pereira E, Vasconcelos M. O processo de socialização no canto coral: um estudo sobre as dimensões pessoal, interpessoal e comunitária. Musica Hodie. 2007;7(1):99-120.

3. Chiarelli LKM, Barreto SJ. A importância da musicalização na educação infantil e no ensino fundamental: a música como meio de desenvolver a inteligência e a integração do ser. Rev Recre@rte. 2005;3:1-10 .

4. Rinta TE, Welch GF. Should singing activities be included in speech and voice therapy for prepubertal children? J Voice. 2008;22(1):100-12. http://dx.doi.org/10.1016/j.jvoice.2006.08.002

5. Webb JL. Promoting vocal health in the choral rehearsal.Music Educ J. 2007;93(5):26-31.

6. Francato A, Nogueira J, Pela SM, Behlau M. Programa de aquecimento e desaquecimento vocal. In: Marchesan IQ, organizator. Tópicos em fonoaudiologia. São Paulo: Lovise; 1996. Vol 3, p. 713-9.

7. Andrade SR, Fontoura DR, Cielo CA. Interrelações entre a fonoaudiologia e o canto. Musica Hodie. 2007;7(1):83-98.

8. Amin E, Espiresz S. Atuação fonoaudiológica no CORALUSP. In: Ferreira LP, Andrada e Silva MA, organizers.Saúde vocal:práticas fonoaudiológicas. São Paulo: Roca; 2002. p. 119-32.

9. Behlau M,organizator. Voz:o livro do especialista. Rio de Janeiro: Revinter; 2005. Vol.2.
10. Stegman SF. Choral warm-ups: preparation to sing, listen and learn. Music Educ J. 2003;37-58.

11. Lazzetta F. Tabela de frequências, períodos e comprimentos de onda [cited 2013 Jan 29]. Available from: http://www.eca.usp.br/prof/iazzetta/ tutor/acustica/introducao/tabela1.html

12. Leão SHS. Análise espectrográfica acústica de vozes rugosas, soprosas e tensas [dissertation]. São Paulo: Universidade Federal do Estado de São Paulo; 2008.

13. Tavares ELM, Labio RB, Martins RHG. Estudo normativo dos parâmetros acústicos vocais de crianças de 4 a 12 anos de idade sem sintomas vocais: estudo piloto. BrazJOtorhinolaryngol. 2010;76(4):48590. http://dx.doi.org/10.1590/S1808-86942010000400013

14. Behlau M, organizator. Voz:o livro do especialista. Rio de Janeiro: Revinter; 2008. Vol 1.

15. Vieira VP, Biase N, Pontes P. Análise acústica e perceptiva auditiva versus coaptação glótica em alteração estrutural mínima. Acta ORL. 2006;24(3):174-80.

16. Titze IR. Choir warm-ups: how effective are they? J Singing. 2000;56(1):31-2.

17. Skelton KD. The child's voice: acloser look at pedagogy and science. J Singing. 2007;63(5):537-44.

18. Sergeant DC, Welch GF. Gender differences in long-term average spectra of children's singing voices. J Voice. 2009;23(3) 319-36. http:// dx.doi.org/10.1016/j.jvoice.2007.10.010.

19. Mc Allister AM, Granqvist S, Sjölander P, Sundberg J. Child voice and noise: a pilot study of noise in day cares and the effects on 10 children's voice quality according to perceptual evaluation. J Voice. 2009;23(5):587-93.http://dx.doi.org/10.1016/j.jvoice.2007.10.017

20. Mecke AC, Sundberg J. Gender differences in children's singing voices: acoustic analyses and results of a listening test. J Acoust Soc Am. 2010;127(5):3223-31. http://dx.doi.org/10.1121/1.3372730.

21. Sundberg J. The science of the singing voice. Cidade: Northern Illinois University Press; 1987.

22. Souza DPD, Silva APBV, Jarrus ME, Pinho SMR. Avaliação fonoaudiológica vocal em cantores infanto-juvenis. Rev CEFAC. 2006;8(2):216-22.

23. Sader RCM, Hanayama EM. Considerações teóricas sobre a abordagem acústica da voz infantil. Rev CEFAC. 2004;6(3):312-8.

\section{Appendix 1. Vocal warm-up for child choristers*}

Vocal warm-up proposal

1. Body and cervical elongation

Stretching arms:

$2 \mathrm{x}$ upwards

$2 x$ sideways

$2 x$ to the other side

Should rotation: $10 \mathrm{x}$ backwards

Head rotation: yes; no and maybe ( $3 x$ each)
2. Articulation exercises

Tongue-in-cheek: $5 \mathrm{x}$ on each side;

Tongue crack: $10 \mathrm{x}$

Triangular smile: $10 \mathrm{x}$;

Kiss: $10 \mathrm{x}$

Exaggerated chewing: $10 x$ 
3. Respiratory exercises - Deep and natural inspiration, releasing air with:

Emission in /s/: $3 x$

Emission in /z/: $3 x$

4. Tongue/lip vibration

Trrr or brrr (same frequency): $10 \mathrm{x}$

Trrr or brrr in ascending or descending glissando: $10 \mathrm{x}$

5. Nasal sounds:

Humming: $10 \mathrm{x}$

In glissando: $10 \mathrm{x}$

In glissando associated with vowels: 10 x (muá, mué, i..., o... u...)

$2 \mathrm{x}$ each series
6. Blowing and fine sound: $5 x$

7. Musical activities:

Arpeggio: $5 \times$ (in 5 different tones: from do to la 3 ) using elements from the do phonemic chart (p,t,k; f,s,x; b,d,g; v,z,j; I,r, rr) in the 5 vowels: a,e,i,o,u

*Procedures for vocal warm-up are based on the following programs: PAD -Vocal Warm-up and Cool-down Program (Francato et al, 1996); chorister vocal preparation (Amin \& Espiresz, 2002); Minimal Physiological Vocal Warm-up and Cool-down Program (Behlau \& cols, 2005) 